\title{
Análise qualitativa da concepção de professores sobre informática na educação
}

\author{
Qualitative analysis on teachers conception about informatics education
}

\author{
Renata Vicente $^{[a]}$, Mara Sizino da Victoria ${ }^{[b]}$, Adriana Benevides Soares ${ }^{[c]}$
}

[a] Especialista em Psicopedagogia, Universidade do Estado do Rio de Janeiro (UERJ), Rio de Janeiro, Rio de Janeiro, RJ - Brasil.

[b] Mestre em Psicologia, Universidade do Estado do Rio de Janeiro (UERJ), Rio de Janeiro, RJ - Brasil, e-mail: marasizino@yahoo.com.br

[c] Doutora em Psicologia, Universidade do Estado do Rio de Janeiro (UERJ), Universidade Salgado de Oliveira (UNIVERSO), Rio de Janeiro, Rio de Janeiro, RJ - Brasil.

\section{Resumo}

Este trabalho buscou fazer uma análise das concepções de 35 professores de $5^{\mathrm{a}}$ a $8^{\mathrm{a}}$ série, no Rio de Janeiro, sobre a informática na educação. A informática vem adquirindo cada vez mais relevância no cenário educacional. Sua utilização como instrumento de aprendizagem e sua ação no meio social vêm aumentando de forma rápida, fazendo a educação passar por mudanças estruturais e funcionais diante dessa nova tecnologia. Por isso, este artigo objetivou, por meio de um instrumento contendo quatro perguntas, fazer uma análise qualitativa do que os professores entendem por informática na educação, quais suas teorias implícitas sobre o processo de aprendizagem dos alunos e a utilização de software educacionais. A análise demonstrou que a maioria dos professores tem uma opinião positiva em relação à inserção da informática na educação, acreditando que ela pode melhorar o processo de aprendizagem, atuando diretamente no desenvolvimento de habilidades cognitivas e no processo motivacional.

Palavras-chave: Concepções de professores. Desenvolvimento cognitivo. Informática na educação.

\begin{abstract}
This research analyzes the conceptions about computers in education from 35 elementary schoolteachers from the state of Rio de Janeiro. Informatics is acquiring more and more relevance in the Brazilian educational scope. Its utilization as a learning tool, and its action in the social scenario, is increasing quickly and changing structural and functional characteristics from education. This research, from four questions, does a qualitative analysis concerning the schoolteachers' comprehension about computers in education, their implicit theories about the learning process, and their
\end{abstract}


opinions about the use of educational software. This analysis has shown that the majority of the schoolteachers has an positive opinion concerning the insertion of computers in education. They affirm that computers may improve the learning process, acting directly on the development of cognitive abilities and on the motivational process.

Keywords: Teachers conceptions. Cognitive development. Educational informatics.

\section{Introduçáo}

A educação brasileira passa por mudanças estruturais e funcionais, em virtude do aumento do número de alunos nas escolas em todos os níveis e também pela inclusão de novas metodologias pedagógicas, em especial a informática. A informática vem adquirindo cada vez mais relevância no cenário educacional, levando os professores a repensar o papel da escola mediante as novas tecnologias (Jacinski \& Faraco, 2002).

A expressão "informática na educação" começa a ser utilizada a partir de 1950, data das primeiras experiências do uso do computador na Universidade de Illinois. Diz respeito à inserção do computador no processo de ensino-aprendizagem de currículos escolares (Valente, 1999). Nos ensinos fundamental e médio, o uso do computador na educação geralmente assume a função de (1) máquinas de ensinar, em que o computador torna-se um recurso para apresentar algum assunto, ou ainda (2) ferramenta, em que os software são usados para que o aluno construa algo e aprenda com o processo (Barros, Wainer, Cláudio, Ferreira \& Dwyer, 2008).

No meio educacional, há uma ideia positiva de que a informática é útil como recurso de ensino fonte. No entanto, o processo de informatização das escolas brasileiras tem se caracterizado, salvo exceções, por uma falta de planejamento pedagógico. De modo geral, preenche-se uma sala de computadores - chamada de laboratório de informática-e contrata-se um especialista em informática com alguma formação em educação para gerenciar o laboratório, e o processo que deveria ser de construção cognitiva termina gerando apenas usuários de computadores sem proporcionar os fins pedagógicos pretendidos (Fagundes, 1996).

No uso do computador para construção do conhecimento, alguns desafios são colocados. Primeiro, o computador precisa ser entendido como uma nova maneira de representar e visualizar o conhecimento, provocando um redimensionamento dos conceitos já conhecidos e possibilitando a busca e compreensão de novas ideias e valores. Usar o computador com essa finalidade requer a análise cuidadosa do que significa ensinar e aprender, bem como rever o papel do professor nesse contexto. Segundo, é preciso haver o entendimento de que o computador pode ser instrumento de construção envolvendo muito mais que o professor com conhecimento de informática. $\mathrm{O}$ uso da informática na educação exige envolvimento do contexto da escola, da prática dos professores e a presença dos processos de formação. Esses aspectos devem oferecer condições para o professor construir conhecimentos sobre técnicas computacionais e entender por que e como integrar o computador na sua prática pedagógica (Araújo \& Benassi, 2005). O processo de integração de computadores e outros instrumentos tecnológicos na escola deve ser compreendidos como um processo de inovação, e como tal afeta fundamentalmente três campos mutuamente ligados: o desenvolvimento profissional do professor, o desenvolvimento organizacional da escola e a reorganização do próprio currículo. As novas tecnologias pressupõem um saber apoiado não em conhecimentos teóricos adquiridos mecanicamente, mas em modelos mentais reflexíveis da realidade, capazes de evoluir em sucessivas e crescentes formalizações (Bayraktar, 2002).

A informática, quando bem planejada e implementada, pode ser um eficiente meio de prevenção das dificuldades de aprendizagem, tendo em vista seus amplos recursos existentes. Por exemplo, existem hoje no mercado diversos software para ensinar conceitos que apresentam difícil assimilação por não existirem aplicações práticas mais imediatas que requeiram capacidade de visualização, como o conceito de eletrização, conservação de energia, trigonometria, grandes navegações, entre outros (Gouvêa, 1999; Fróes, 2004; Araújo \& Benassi, 2005). Pesquisas desenvolvidas no Brasil e no exterior informam que escolas que utilizam computadores no processo de 
ensino-aprendizagem apresentam melhorias nas condições de estruturação do pensamento do aluno com dificuldades de aprendizagem, compreensão e retenção do conhecimento. Colaboram também para melhorar a aprendizagem de conceitos matemáticos, já que o computador pode constituir-se num bom gerenciador de atividades intelectuais, desenvolver a compreensão de conceitos matemáticos, promover o texto simbólico capaz de desenvolver o raciocínio sobre ideias matemáticas abstratas, além de tornar a criança mais consciente dos componentes superiores do processo de escrita (Moraes, 1998; Atkinson, 2004; Magliano, Todaro, Millins, Wiemer-Hastings, Kim \& McNamara, 2005).

Por tudo isso, é necessário refletire compreender a forma que os professores vêm concebendo essa nova tecnologia na educação. Nesse sentido, os objetivos deste trabalho foram investigar:

1) o que os professores de $5^{\mathrm{a}}$ a $8^{\mathrm{a}}$ séries entendem por informática na educação;

2) se a tecnologia informacional pode ajudar no processo de aprendizagem dos alunos;

3) as concepções implícitas que os professores têm sobre os software educacionais e seus benefícios segundo o tempo de magistério exercido (de 0 a 10 anos, de 11 a 20 anos e com mais de 20 anos de exercício da profissão).

\section{Método}

\section{Participantes}

Participaram desta pesquisa 35 professores $(88,57 \%$ do sexo feminino e $11,42 \%$ do sexo masculino) de $5^{\text {a a }} 8^{\text {a }}$ séries, do Rio de Janeiro, distribuídos pelas seguintes áreas das ciências: humanas (20\%), naturais $(5,71 \%)$, exatas $(22,85 \%)$, letras e artes $(51,42 \%)$. A experiência profissional dos professores variava de $60 \%$, de 0 a 10 anos de magistério ( $\mathrm{N}=$ 21); $22,86 \%$, de 11 a 20 anos ( $N=8)$; e 17,14\%, com mais de 20 anos de atuação $(\mathrm{N}=6)$. Em função da rede de ensino, os participantes se distribuíram em professores da rede pública $(60 \%)$, professores da rede particular $(31,42 \%)$ e professores que atuam na rede pública e privada $(8,57 \%)$.

\section{Instrumento}

O questionário foi elaborado para esta pesquisa e apresentado aos sujeitos em forma de quatro perguntas abertas:

Questão 1 - O que você entende por informática na educação (também conhecida como Informática Educacional)?

Questão 2 - Você acha que a informática na educação pode melhorar o processo de aprendizagem dos alunos? Justifique sua resposta.

Questão 3 - Você acha relevante utilizar software educacionais, para desenvolver habilidades cognitivas, com seus alunos? Justifique sua resposta.

Questão 4 - Você acha importante utilizar software educacionais para desenvolver conteúdos específicos, com seus alunos? Justifique.

\section{Procedimentos}

Os participantes responderam as questões em tempo livre. As respostas foram examinadas segundo a análise de conteúdo de Bardin (2006), identificando os itens revelados nas respostas dos professores de forma a contemplar duas categorias previamente estabelecidas: ferramenta capaz de atuar no desenvolvimento cognitivo dos alunos ou ferramenta que serve apenas como mais um recurso didático complementar. Todas as respostas foram avaliadas por pelo menos dois juízes.

\section{Resultados}

Todas as tabelas foram distribuídas por tempo de magistério dos professores, de 0 a 10 anos, de 11 a 20 anos e com mais de 20 anos de exercício da profissão.

As respostas de cada questão foram divididas sempre em duas categorias. Essas categorias foram eleitas por serem as características que mais se repetiam nas respostas dos professores e porque revelavam pressuposições de valorização da ferramenta informacional como capaz de promover o desenvolvimento cognitivo ou ser apenas um complemento pedagógico. 


\section{Análise da Questão 1}

As respostas foram separadas em duas categorias: argumentos em favor do desenvolvimento cognitivo e argumentos em favor do complemento instrucional.

Os argumentos em favor do desenvolvimento cognitivo foram agrupados para categorizar respostas que enfatizam a informática na educação como uma forma de desenvolver habilidades de cognição, ou seja, o sistema cognitivo interage com o ambiente informacional captando dados que, após serem processados, assumem a forma de conhecimentos. Por meio de múltiplas interações, esse sistema passa por mudanças evolutivas que ampliam a capacidade de utilizar essas informações para integrar-se da melhor forma ao mundo.

Os argumentos em favor do complemento instrucional agrupam respostas que retratam que a informática na educação complementa atividades realizadas em sala de aula, tornando, assim, o computador mais um aliado à educação, trazendo de uma forma diferente e inovadora um complemento técnico aos novos conhecimentos, auxiliando na produção de trabalhos, na estimulação do visual, nas simulações, na interdisciplinaridade etc. (Tabela 1).

Foram apresentados como argumentos em favor do desenvolvimento cognitivo que a informática é uma técnica de aprendizagem que serve para o desenvolvimento cognitivo, para adquirir conhecimento, para o desenvolvimento de habilidades e competências.

Dos professores de 0 a 10 anos de magistério, $2,86 \%$ acham que ela atua no desenvolvimento de habilidades e competências. Entre os profissionais com 11 a 20 anos de magistério, 5,71\% argumentam que a informática é uma forma de adquirir conhecimentos. Já entre os professores com mais de 20 anos de magistério, 5,71\% a entendem como uma técnica de aprendizagem, 2,86\% acham que desenvolve as capacidades cognitivas, $2,86 \%$ acham que é uma forma de adquirir conhecimento.

Em favor do complemento instrucional, temos os argumentos de que a informática propicia a interdisciplinaridade, serve como ferramenta de trabalho, é uma nova tecnologia, auxilia o professor, é um complemento didático e serve para a inclusão digital.

Entre os professores de 0 a 10 anos de magistério, $5,71 \%$, pensam que a informática

Tabela 1 - Distribuição da amostra por tempo de magistério

\begin{tabular}{|c|c|c|c|c|c|}
\hline \multicolumn{2}{|r|}{ Itens } & \multicolumn{4}{|c|}{ Tempo de magistério } \\
\hline \multirow{4}{*}{$\begin{array}{l}\text { Argumentos } \\
\text { a favor do } \\
\text { desenvol- } \\
\text { vimento } \\
\text { cognitivo }\end{array}$} & & 0 a 10 anos & 11 a 20 anos & Mais de 20 anos & Total \\
\hline & Técnica de aprendizagem & - & - & $2-5,71 \%$ & $2-5,71 \%$ \\
\hline & Desenvolvimento cognitivo & - & - & $1-2,86 \%$ & $1-2,86 \%$ \\
\hline & Aquirir conhecimento & - & $2-5,71 \%$ & $1-2,86 \%$ & $3-8,57 \%$ \\
\hline \multirow{7}{*}{$\begin{array}{l}\text { Argumentos } \\
\text { a favor do } \\
\text { complemento } \\
\text { instrucional }\end{array}$} & $\begin{array}{l}\text { Desenvolvimento de } \\
\text { habilidades e competências }\end{array}$ & $1-2,86 \%$ & - & - & $1-2,86 \%$ \\
\hline & Interdisciplinaridade & $2-5,71 \%$ & $1-2,86 \%$ & - & $3-8,57 \%$ \\
\hline & Ferramenta de trabalho & $1-2,86 \%$ & $1-2,86 \%$ & - & $2-5,71 \%$ \\
\hline & Nova tecnologia & $3-8,57 \%$ & $2-5,71 \%$ & - & $5-14,29 \%$ \\
\hline & Auxílio ao professor & $6-17,14 \%$ & - & $2-5,71 \%$ & $8-22,85 \%$ \\
\hline & Complemento & $5-14,29 \%$ & $2-5,71 \%$ & - & $7-20 \%$ \\
\hline & Inclusão digital & $3-8,57 \%$ & - & - & $3-8,57 \%$ \\
\hline
\end{tabular}


educacional atua na interdisciplinaridade, 2,86\% acreditam que é mais uma ferramenta de trabalho, $8,57 \%$ imaginam que é apenas uma nova tecnologia, $17,14 \%$ acham que a iformática pode auxiliar no trabalho do professor com os alunos, 14,29\% acreditam que pode ser uma forma de complementar a matéria dada em sala de aula, e 8,57\% acreditam que se trata apenas de uma forma de inclusão digital sem muitas funções educacionais.

Dos profissionais entre 11 e 20 anos de magistério, $2,86 \%$ concordam que é uma forma de interdisciplinar de aprender os conteúdos, 2,86\% acham que é mais uma ferramenta de trabalho, $5,71 \%$ acreditam que é apenas mais uma nova tecnologia e $5,71 \%$ pensam que pode ser mais uma forma de complementar o conteúdo trabalhado em sala de aula.

Entre os professores com mais de 20 anos de magistério, 5,71\% acham que a informática educacional pode dar um auxílio ao trabalho do professor com os alunos.

\section{Análise da Questáo 2}

As respostas foram categorizadas em dois tipos: respostas positivas, aquelas em que os professores concordam que a informática pode melhorar o processo de aprendizagem dos alunos, e as respostas negativas, em que os professores não acham que a informática possa melhorar o processo de aprendizagem dos alunos. As respostas positivas foram categorizadas segundo as argumentações favoráveis ao desenvolvimento cognitivo e as favoráveis à motivação no ensino. O desenvolvimento cognitivo como justificativa baseia-se na ideia de que é possível melhorar o processo de aprendizagem porque auxilia no processo de pensamento e construção de conhecimento dos alunos. Já a motivação justifica-se pelo fato de que melhora o processo de ensino e aprendizagem por ser uma ferramenta estimuladora, já que faz uso de recursos visuais, auditivos, animação, simulação etc. Dessa forma, motiva os alunos a estudar os conteúdos das matérias trabalhadas em sala de aula (Tabela 2).

Tabela 2 - Distribuição da amostra por tempo de magistério

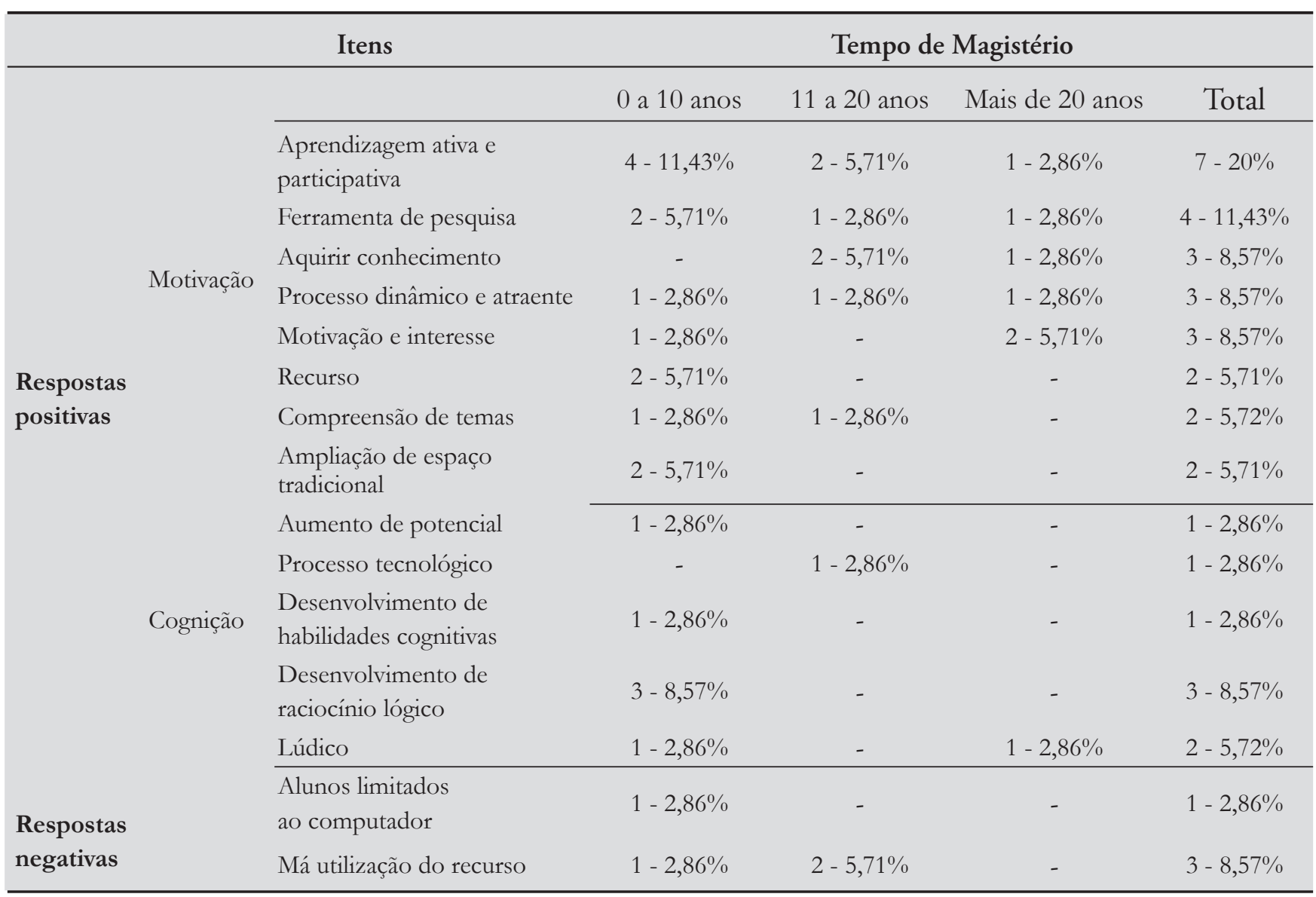


Das respostas positivas utilizando argumentos de motivação temos o entendimento de que a informática permite uma aprendizagem ativa e participativa, serve como ferramenta de pesquisa, é um processo dinâmico e atraente, motiva e interessa, é mais um recurso, serve para a compreensão de temas, é uma ampliação do espaço tradicional.

Dos professores de 0 a 10 anos de magistério, $11,43 \%$ acham que a informática educacional pode melhorar o processo de aprendizagem dos alunos porque é uma aprendizagem ativa e participativa; $5,71 \%$ pensam que melhora porque é mais uma ferramenta que pode ser utilizada para pesquisas; $2,86 \%$ acreditam que a informática seja um processo dinâmico e atraente para o aluno; 2,86\% acham que por meio da informática os alunos terão motivação e interesse para a aprendizagem; 5,71\% acreditam que a informática seja mais um recurso para o aluno adquirir conhecimentos; $2,86 \%$ pensam que auxilia na compreensão de temas e ainda 5,71\% admitem que é uma ampliação do espaço tradicional.

Dos profissionais com 11 a 20 anos de magistério, 5,71\% acham que a informática melhora o processo de aprendizagem porque este processo tende a se tornar ativo e participativo, $2,86 \%$ pensam que é mais uma ferramenta para ser utilizado em pesquisas, $2,86 \%$ acham que é um processo dinâmico e atraente para o aluno e $2,86 \%$ admitem que auxilia na compreensão de temas.

Dos professores com mais de 20 anos de aprendizagem, 2,86\% acham que a informática melhora o processo de aprendizagem porque ela tende a se tornar ativa e participativa, 2,86\% acham que é mais uma ferramenta utilizada para pesquisas, $2,86 \%$ acham que é um processo dinâmico e atraente, $5,71 \%$ acreditam que a informática tende a despertar a motivação e o interesse nos alunos.

Das respostas positivas com argumentos em favor da cognição, temos a concepção que a informática serve para o desenvolvimento de habilidades, para o progresso tecnológico, para o desenvolvimento de habilidades cognitivas, para o desenvolvimento do raciocínio lógico, e para atividades lúdicas.

Entre os professores de 0 a 10 anos de magistério, $2,86 \%$ acham que a informática educacional melhora no processo de aprendizagem porque desenvolve o potencial do aluno, 2,86\% acreditam que a informática tende a desenvolver habilidades cognitivas, melhorando assim a aprendizagem, $8,57 \%$ imaginam que desenvolve o raciocínio lógico e 2,86\% acreditam que a informática, por ter formas lúdicas de transmitir informações, tende a melhorar o processo de aprendizagem.

Dos profissionais de 11 a 20 anos de magistério, 2,86\% pensam que a informática melhora o processo de aprendizagem porque é um progresso tecnológico que veio para auxiliar no processo de aprendizagem. Entre aqueles com mais de 20 anos de magistério, 2,86\% acreditam que a informática, por ter formas lúdicas de transmitir informações, tende a melhorar o processo de aprendizagem.

Das respostas negativas, $2,86 \%$ dos professores de 0 a 10 anos de magistério acham que a informática não auxilia no processo de aprendizagem porque os educandos não sabem utilizar corretamente esta nova tecnologia, além de os alunos ficarem limitados ao computador. De 11 a 20 anos de magistério, 5,71\% dos professores acreditam que com a informática os alunos ficariam limitados às informações do computador.

\section{Análise da Questão 3}

As respostas foram divididas em dois grupos: as respostas positivas e negativas. As respostas positivas são aquelas em que os professores acham relevante a utilização de software educacionais para desenvolver habilidades cognitivas. As respostas negativas são de professores que negam essa possibilidade de desenvolvimento.

As respostas positivas foram categorizadas segundo aos argumentos cognitivos e os argumentos favoráveis ao complemento instrucional.

Os argumentos em favor da cognição refletem a relevância da utilização dos software para os professores, já que estes vêm a auxiliar no processo de construção do conhecimento a partir das atividades propostas.

Os argumentos a favor do complemento instrucional mostram que a utilização de software educacionais é relevante porque estes agrupam conteúdos que podem ser explorados de forma lúdica, complementando assim os conteúdos trabalhados em sala de aula (Tabela 3). 
Tabela 3 - Distribuição da amostra por tempo de magistério

\begin{tabular}{|c|c|c|c|c|c|c|}
\hline & \multicolumn{2}{|r|}{ Itens } & \multicolumn{4}{|c|}{ Tempo de magistério } \\
\hline \multirow{11}{*}{$\begin{array}{l}\text { Respostas } \\
\text { positivas }\end{array}$} & \multirow{5}{*}{$\begin{array}{l}\text { Argumentos } \\
\text { cognitivos }\end{array}$} & & 0 a 10 anos & 11 a 20 anos & Mais de 20 anos & Total \\
\hline & & Criatividade & - & $1-2,86 \%$ & $1-2,86 \%$ & $2-5,72 \%$ \\
\hline & & Auxílio no raciocínio & $2-5,71 \%$ & - & $1-2,86 \%$ & $3-8,57 \%$ \\
\hline & & $\begin{array}{l}\text { Desenvolvimento de } \\
\text { habilidades cognitivas }\end{array}$ & $7-20 \%$ & $3-8,57 \%$ & $2-5,71 \%$ & $12-34,28 \%$ \\
\hline & & $\begin{array}{l}\text { Entrelace entre habilidades } \\
\text { de observação, análise, } \\
\text { síntese e operacionalização }\end{array}$ & - & $1-2,86 \%$ & - & $1-2,86 \%$ \\
\hline & \multirow{7}{*}{$\begin{array}{l}\text { Argumentos } \\
\text { de com- } \\
\text { plemento } \\
\text { instrucional }\end{array}$} & Resolução de problemas & $1-2,86 \%$ & - & - & $1-2,86 \%$ \\
\hline & & Estimula o pensar & $1-2,86 \%$ & - & - & $1-2,86 \%$ \\
\hline & & Reforço de conteúdo & - & $1-2,86 \%$ & $1-2,86 \%$ & $2-5,72 \%$ \\
\hline & & $\begin{array}{l}\text { Processo dinâmico de } \\
\text { aprendizagem }\end{array}$ & $2-5,71 \%$ & - & $1-2,86 \%$ & $3-8,57 \%$ \\
\hline & & $\begin{array}{l}\text { Melhora o desempenho } \\
\text { dos alunos }\end{array}$ & $1-2,86 \%$ & - & - & $1-2,86 \%$ \\
\hline & & $\begin{array}{l}\text { Informação em diferentes } \\
\text { linguagens }\end{array}$ & $1-2,86 \%$ & - & - & $1-2,86 \%$ \\
\hline \multirow{3}{*}{$\begin{array}{l}\text { Respostas } \\
\text { negativas }\end{array}$} & & Conhecimentos novos & $3-8,57 \%$ & - & - & $3-8,57 \%$ \\
\hline & & Software mal formulados & $2-5,71 \%$ & $1-2,86 \%$ & - & $3-8,57 \%$ \\
\hline & & Má utilização dos software & - & $1-2,86 \%$ & - & $1-2,86 \%$ \\
\hline
\end{tabular}

Das respostas positivas utilizando argumentos cognitivos, temos o entendimento de que os software educacionais podem desenvolver a criatividade, auxiliar no raciocínio, desenvolver habilidades cognitivas, entrelaçar habilidades de observação, análise, síntese e operacionalização, ajudar a resolver problemas, estimular o pensar.

Entre os professores de 0 a 10 anos de magistério, 5,71\% acreditam ser relevante a utilização de software educacionais para desenvolver as habilidades cognitivas, porque auxilia no raciocínio, $20 \%$ admitem que realmente os software desenvolvem habilidades cognitivas, 2,86\% acham que os software auxiliam na resolução de problemas e $2,86 \%$ pensam que estimula o pensar.

Dos profissionais de 11 a 20 anos de magistério, 2,86\% acreditam que é relevante a utilização de software educacionais porque estes estimulam a criatividade, $8,57 \%$ imaginam que realmente a habilidade cognitiva pode ser desenvolvida, 2,86\% acham que a utilização dos software entrelaça habilidades de observação, análise, síntese e operacionalização.

Dos profissionais com mais de 20 anos de magistério, 2,86\% imaginam que é relevante a utilização de software educacionais no desenvolvimento de habilidades cognitivas porque estimulam a criatividade, $2,86 \%$ pensam que os software podem auxiliar no raciocínio e $5,71 \%$ acham que o cognitivo pode realmente ser desenvolvido.

Das respostas positivas com argumentos a favor do complemento instrucional temos a ideia de que os software servem como reforço de conteúdo, complemento de aulas, um processo dinâmico de aprendizagem, elemento de melhora do desempenho dos alunos, informação em diferentes linguagens e conhecimentos novos.

Entre os professores com 0 a 10 anos de magistério, 2,86\% acreditam ser relevante a utilização de software educacionais para desenvolver as habilidades cognitivas porque complementa as aulas, 
5,71\% acham que é um processo dinâmico de aprendizagem, $2,86 \%$ pensam que melhora o desempenho dos alunos, $2,86 \%$ admitem que os software trazem informações em diferentes linguagens e $8,57 \%$ acham que trazem novas informações.

Dos profissionais de 11 a 20 anos de magistério $2,86 \%$ acham que é relevante a utilização de software educacionais no desenvolvimento de habilidades cognitivas porque podem estar reforçando o conteúdo trabalhado em sala de aula.

Entre os profissionais com mais de 20 anos de magistério, 2,86\% pensam que é relevante a utilização de software educacionais no desenvolvimento de habilidades cognitivas porque são elementos para um processo dinâmico de aprendizagem e 2,86\% acreditam que reforça o conteúdo de sala de aula.

Das respostas negativas, $2,86 \%$ dos professores de 11 a 20 anos de magistério acham que a utilização de software não desenvolve habilidades cognitivas porque os educandos não sabem utilizar corretamente esta nova tecnologia; $5,71 \%$ dos professores de 0 a 10 anos de magistério e 2,86\% de 11 a 20 anos acham que os software são mal formulados.

\section{Análise da Questáo 4}

As respostas foram divididas em dois tipos: respostas positivas e negativas (Tabela 4). As

Tabela 4 - Distribuição da amostra por tempo de magistério

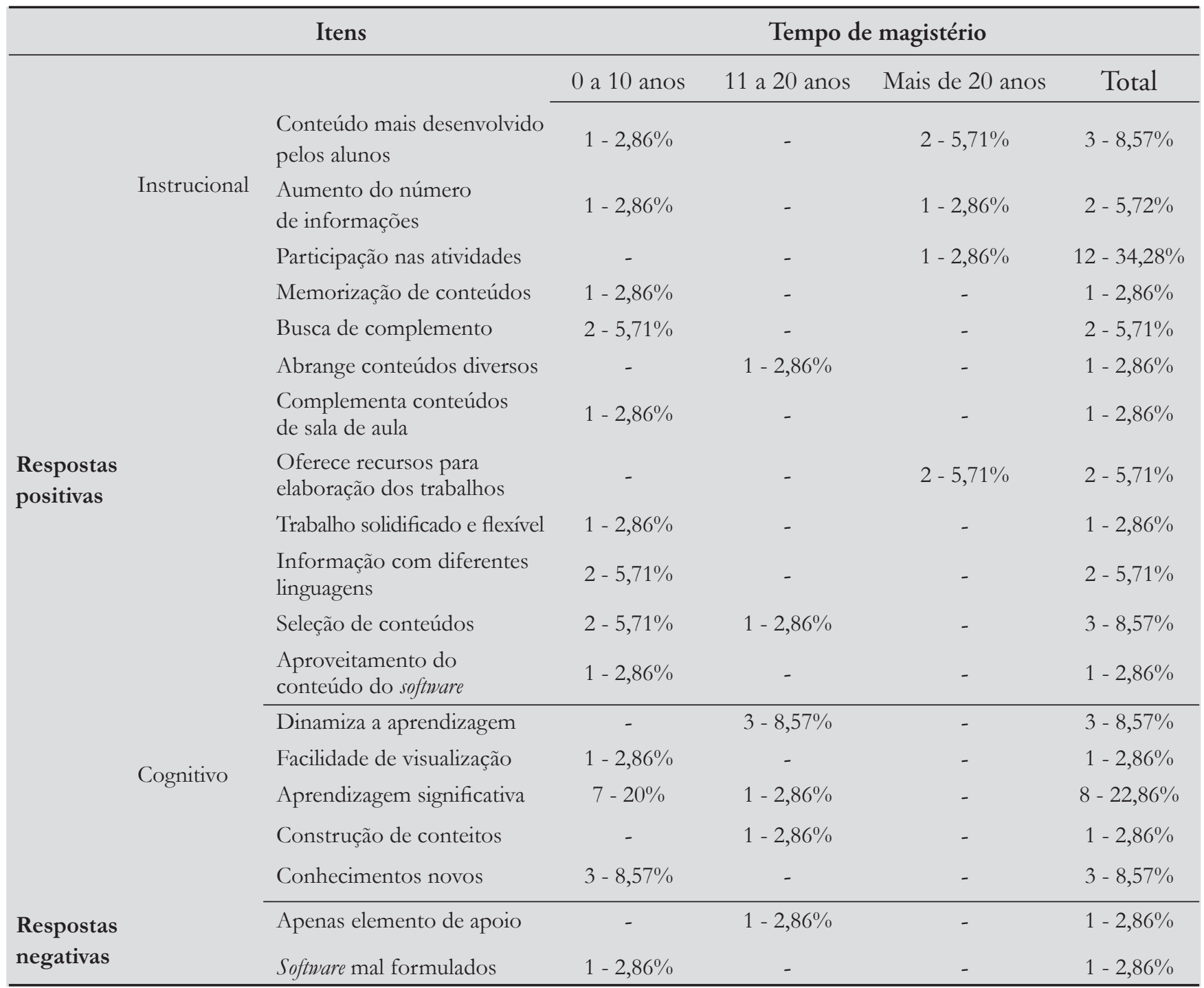


respostas positivas são respostas cujos professores acham relevante à utilização de software educacionais para desenvolver conteúdos específicos. As respostas negativas são de professores que negam a possibilidade do desenvolvimento desses conteúdos. As respostas positivas foram categorizadas segundo os argumentos em favor do desenvolvimento cognitivo ou em favor de uma ampliação do conteúdo instrucional.

Os argumentos em favor do desenvolvimento cognitivo refletem a importância da utilização dos software com conteúdos específicos, já que estes vêm a auxiliar no processo de construção do conhecimento a partir das atividades direcionadas a uma matéria específica.

Os argumentos em favor da ampliação instrucional mostram que a utilização de software com conteúdos específicos auxilia o professor na transmissão de conhecimentos para os alunos, fazendo deste material um complemento diferenciado, com áudio, visão e interação para exemplificar tais conteúdos.

Das respostas positivas utilizando argumentos instrucionais, temos identificado o pensamento de que software educacionais são formas de obter conteúdo mais desenvolvido para os alunos, servem para o aumento do número de informações, participação nas atividades, memorização de conteúdos, busca de complemento, servem para abranger conteúdos diversos, servem para complementar os conteúdos de sala de aula, oferecem recursos para elaboração dos trabalhos, servem para desenvolver um trabalho solidificado e flexível, informam com diferentes linguagens, permitem a seleção de conteúdos e o aproveitamento do conteúdo do software.

Dos professores de 0 a 10 anos de magistério, 2,86\% acham relevante a utilização de software educacionais para desenvolver conteúdos específicos porque o conteúdo pode ser mais desenvolvido pelo aluno, 2,86\% imaginam que aumenta o número de informações para os alunos, $2,86 \%$ acreditam que os conteúdos serão memorizados com mais facilidade, $5,71 \%$ imaginam que a tecnologia complementa as informações já adquiridas, 2,86\% pensam que os software trazem um conteúdo mais sólido e flexível e complementam conteúdos de sala de aula, 5,71\% acham que os software trazem informações em diferentes linguagens, $5,71 \%$ argumentam que os conteúdos são selecionados ajudando no desenvolvimento dos conteúdos específicos, $2,86 \%$ imaginam que, com um software educacional específico, o conteúdo pode ser mais desenvolvido pelo aluno.

Dos profissionais com 11 a 20 anos de magistério, 2,86\% admitem ser relevante a utilização de software educacionais para o desenvolvimento de conteúdos específicos porque o software abrange conteúdos mais diversificados, 2,86\% acreditam que os conteúdos são selecionados, ajudando no desenvolvimento dos conteúdos específicos.

Dos professores com mais de 20 anos de magistério, $5,71 \%$ acham relevante a utilização de software educacionais para o desenvolvimento de conteúdos específicos, porque com um software educacional o conteúdo pode ser mais desenvolvido pelo aluno; $2,86 \%$ argumentam que com a utilização dos software o número de informações aumenta; $2,86 \%$ acreditam que os alunos podem participar mais das atividades trabalhando com um software; $5,71 \%$ pensam que os software oferecem recursos para elaboração de trabalhos escolares.

Das respostas positivas com argumentos do desenvolvimento cognitivo, temos o entendimento de que os software educacionais dinamizam a aprendizagem, facilitam a visualização, permitem a aprendizagem significativa e construção de conceitos. Dos professores de 0 a 10 anos de magistério, 2,86\% acham relevante a utilização de software educacionais para o desenvolvimento de conteúdos específicos porque acham que o software traz uma facilidade de visualização de conteúdos que muitas vezes não é observável em uma sala de aula tradicional; $20 \%$ acreditam que os software trazem uma aprendizagem significativa.

Dos professores com 11 a 20 anos de magistério, $8,57 \%$ pensam ser relevante a utilização de software educacionais para o desenvolvimento de conteúdos específicos porque, com a utilização de software, a aprendizagem fica mais dinâmica; 2,86\% admitem que os software trazem uma aprendizagem significativa e $2,86 \%$ acham que auxilia na construção de conceitos.

Das respostas negativas, $2,86 \%$ dos professores de 11 a 20 anos de magistério não acham relevante a utilização de software educacionais para desenvolvimento de conteúdos específicos porque consideram que seja apenas um elemento de apoio e não algo que venha a fazer diferença se não for utilizado. Dos professores de 0 a 10 anos de magistério, 2,86\% argumentam que os software são mal formulados e, com isso, não são relevantes. 


\section{Discussão}

$\mathrm{Na}$ Questão 1 podemos verificar o que o professor entende por informática educacional. Os professores com até 10 anos de magistério entendem que a informática educacional é um complemento instrucional. $\mathrm{O}$ argumento mais utilizado é que esse processo auxilia o professor no desenvolvimento de seus conteúdos, servindo como complemento para as matérias aprendidas em sala de aula. Nesse sentido, quando a informática é utilizada dessa maneira na escola, a informática a serviço de um projeto educacional pode propiciar condições para que os alunos trabalhem a partir de temas, projetos ou atividades surgidos no contexto da sala de aula. Em decorrência dessas situações, os alunos podem contar com a interatividade e os programas oferecidos pelo computador.

A partir dessas respostas, percebemos a importância que os professores têm dado à informática, em especial os com até 10 anos de magistério, querendo que esta venha a fazer parte da realidade escolar, acrescentando e complementando os conteúdos trabalhados em sala de aula. Alguns professores da mesma área de atuação, com mais de 20 anos de magistério da rede pública, entendem que a informática educacional auxilia no desenvolvimento cognitivo. $\mathrm{O}$ argumento mais utilizado é que a informática é um meio de adquirir conhecimento. Esses professores entendem que a informática educacional é um complemento cognitivo, pelo fato de do computador estar estimulando o processo de pensamento dos alunos. Por meio do desenvolvimento de software direcionados às matérias dadas em sala de aula, criação de projetos, montagem de textos, a informática poderia estar estimulando o processo de aquisição de conhecimento.

Dessa forma, percebemos que os professores jovens na carreira docente dão um valor complementar à informática, enquanto os mais experientes atribuem um papel de construção do conhecimento. Essa questão reflete o momento da utilização da informática na nossa sociedade. Os professores com menor tempo de experiência estudaram em uma época em que a informática era mais usual e, portanto, para esses, a inclusão deste recurso é mais natural, enquanto os mais experientes pouco contato tiveram com essa tecnologia no seu dia a dia. Eis uma das dificuldades da inclusão dessa tecnologia: os professores, principalmente aqueles com mais tempo de magistério, não percebem o potencial dessa ferramenta porque não tiveram uma formação que incluísse a informática. Por isso, para eles, esse recurso não faz parte da linguagem do ensino e sim é algo externo - tem a função de adquirir informação (Jacinski \& Faraco, 2002).

$\mathrm{Na}$ Questão 2 podemos identificar a posição do professor diante da informática educacional e o processo de ensino aprendizagem. A maioria dos professores $(86 \%)$ acredita que a informática melhora o processo de aprendizagem dos alunos.

Os profissionais com até 10 anos de magistério acham que a informática melhora a aprendizagem do aluno por ser um meio motivador de transmitir informações, já que esse meio dispõe de uma tecnologia que possibilita ao aluno visualizar em um só espaço realidades diferentes e em lugares diferentes. Os professores definem a informática educacional como uma atividade motivadora por acreditarem que os alunos desenvolvem as atividades no computador com prazer e com interesse enorme pelas atividades ali desenvolvidas. Os alunos se sentem motivados pelo fato de se sentirem realmente produtores de seus conhecimentos, já que o computador permite que haja interação com o meio. Com esse recurso tecnológico é possível que o aluno busque outras informações a partir daquela já proposta e, pela densidade de informações que lhe é disponibilizado, ele se sente motivado a buscar novos conhecimentos, dando oportunidade a uma aprendizagem ativa, o aluno aprendendo fazendo.

De todos os professores, 65,72\% têm o argumento fundamentado na motivação, em especial a possibilidade de uma aprendizagem ativa e participativa - ou seja, o aluno tem uma aprendizagem mais significativa, aprendendo fazendo, e ainda pode participar do processo da construção desse conhecimento. Os professores que não concordam $(11,40 \%)$ que a Informática melhora o processo de aprendizagem utilizam como argumentos que os alunos ficam limitados apenas às informações do computador, deixando de ir a bibliotecas e lerem livros. Outro argumento também utilizado é que os professores ainda não sabem utilizar esse novo recurso. Neste argumento, pode-se verificar que ainda há uma resistência no uso de novas tecnologias. Incluir a Informática é incluir novas maneiras de pensar, estabelecer novas relações entre os homens, $\mathrm{O}$ trabalho e até a própria inteligência. A própria escrita, 
leitura, nossos sentidos, o ato de criação e formas de comunicação sofrem uma transformação com a inclusão da informática. Isso mostra a necessidade de um planejamento pedagógico para o uso da informática nas escolas brasileiras (Fagundes, 1996). Mas mesmo com as dificuldades na inserção de novos recursos, na nossa pesquisa, a maioria dos professores $(88,60 \%)$ acredita que a informática na educação melhora o processo de aprendizagem porque esta vem a atuar diretamente no desenvolvimento de habilidades cognitivas e no processo motivacional.

$\mathrm{Na}$ Questão 3 podemos verificar o quanto o professor acha relevante o uso de software educacionais para desenvolver habilidades cognitivas. Os professores com até 10 anos de magistério acham relevante a utilização de software, e os argumentos utilizados para tal conclusão são que os software desenvolvem as habilidades cognitivas dos alunos, auxiliam o raciocínio, ajudam na resolução de problemas, estimulam o pensamento e a criatividade. Um fator importante à concepção de software educacional é que este seja "interativo", isto é, o aluno deve estar em comunicação com o sistema e vice-versa. Essa interação pode ocorrer por meio da resolução de problemas, análise de representações gráficas, simulação, participação ativa no próprio ambiente e, principalmente, pela criação de seus próprios mundos virtuais para serem explorados. Assim, os professores respondentes dessas questões veem o software atendendo à expectativa deles com relação à aquisição de conhecimentos.

Alguns professores $(31,44 \%)$ pensam que utilizar software educacionais é um complemento instrucional, pois auxiliam num processo dinâmico de aprendizagem, melhorando o desempenho dos alunos nas matérias trabalhadas. No entanto, a maioria $(57,15 \%)$ pensa que utilizar software educacionais auxilia no desenvolvimento de habilidades cognitivas, ajuda na resolução de problemas e estimula o pensamento. Os professores que não concordam que o software educacional desenvolve habilidades cognitivas $(11,43 \%)$ utilizam os argumentos que esses software são mal formulados e não atendem às suas expectativas, e sua utilização não é correta. Isso nos leva a pensar no desconhecimento do material disponível em software, já que muitos assuntos poderiam ser transmitidos de forma mais interessantes e até melhor compreendidos com os recursos informatizados. O computador traz a potencialidade de pesquisar, simular situações, testar conhecimentos específicos, descobrir novos conceitos, lugares eideias. O professor pode direcionar o uso da informática em busca de uma aprendizagem significativa, como o uso de jogos educativos e sites educacionais, e não apenas como fonte de diversão (Moran, 2004).

$\mathrm{Na}$ Questão 4 podemos verificar o quanto o professor acha importante o uso de software educacionais para desenvolver conteúdos específicos. A maior parte dos professores tem uma visão positiva sobre esse assunto (94,28\%). Há uma variedade enorme de software de Português e Artes no mercado que atendem bem às expectativas dos professores desta área, segundo respostas dadas ao questionário. Contendo exercícios que podem ser bastante explorados e exercitados para a fixação do conteúdo, os alunos se sentem motivados a resolver os problemas oferecidos pelo software, já que os exercícios aparecem de uma forma lúdica. Das respostas negativas, apenas $5,72 \%$ dos professores acham que alguns software são mal formulados, não atendendo às suas expectativas, ou servem apenas como elemento de apoio. Desta forma, podemos afirmar que a informática é um potencial recurso no processo ensino-aprendizagem. Por meio dela é possível construir conhecimentos e ideias que, em uma aula tradicional, talvez não fossem desenvolvidos. A informática é um meio de trabalho atraente, com diversas possibilidades de interação, de comunicação e de crescimento pessoal e educacional. Por meio do professor, proporciona uma interação entre a tecnologia e seus alunos de maneira eficaz, fazendo que eles construam conhecimentos planejados de forma dinâmica e satisfatória. Não aceitar a utilização de novas tecnologias é abster-se de propiciar aos alunos novas ideias e ações em sala de aula (Moran, 2004; Valente, 1999).

\section{Consideraçóes finais}

Nossa pesquisa corrobora a opinião favorável de que a informática é parte importante no processo ensino-aprendizagem, concordando com o que avança Barros et al. (2008). No entanto, há muito que fazer no que se refere à preparação de professores na orientação do aluno diante desses novos conceitos e novas relações que surgem no mundo tecnológico. Embora os professores deste estudo apresentem uma visão positiva sobre o assunto, há muitas questões que permeiam a área, como: quais aspectos cognitivos podem ser facilitados pelo uso 
da informática? Quais os benefícios da inclusão do computador na educação como um todo? No mundo atual, em que o computador é indispensável para a maioria das pessoas, qual o grau de participação que a informática deve ter no meio escolar? E ainda, como preparar o professor para uso dessa tecnologia no seu dia a dia escolar?

Este estudo assume a posição de que o uso do computador pode funcionar como instrumento no processo de ensino-aprendizagem se for inserido num contexto de atividades que desafiem o grupo em seu crescimento. Espera-se então, a partir daí, que o aluno construa seu conhecimento, na relação com o outro (o professor e os colegas), com a máquina e consigo. Tendo em vista tal necessidade de o professor estar envolvido com este meio tecnológico atual, seria necessário que fosse inserido na grade curricular de formação deste professor para a utilização da informática. Assim, ele estaria preparado para desenvolver atividades paralelas no computador sem dificuldades, possibilitando aos alunos uma aula mais dinâmica e com possibilidade de construção de conhecimento.

\section{Referências}

Araújo, S. L. S., \& Benassi, K. P. (2005). O uso dos recursos da informática como instrumento mediador no processo de ensino-aprendizagem de pessoas com necessidades educativas especiais: Um relato de experiência. Revista Brasileira de Informática na Educação, 13(2), 65-70.

Atkinson, S. A. (2004). Comparison of pupil learning and achievement in computer aided learning and traditionally taught situations with special reference to cognitive style and gender issues. Educational Psychology, 24(5), 659-679.

Barros, A. C., Wainer, J., Cláudio K., Ferreira, L. R. R., \& Dwyer, T. (2008). Uso de computadores no ensino fundamental e médio e seus resultados empíricos: Uma revisão sistemática da literatura. Revista Brasileira de Informática na Educação, 16(1), 1-14.

Bayraktar, S. (2002). A meta-analysis of the effectiveness of computer-assisted instruction in science educational. Journal of Research on Technology in Education, 34(2), 173-188.

Bardin, L. (2006).Análise de conteúdo.Lisboa:Edições 70.
Fagundes, L. C. (1996). Problemas de desenvolvimento cognitivo e a interação com a tecnologia. In V. B. Oliveira (Org.). Informática em psicopedagogia (pp. 15-34). São Paulo: SENAC.

Fróes, J. R. M. Educação e informática: A relação homem/máquina e a questão da cognição. Recuperado em 10 abr. 2004 em http:/ / www.proinfo. gov.br/biblioteca/textos/txtie4doc.pdf.

Gouvêa, S. F. (1999). Os caminhos do professor na era da tecnologia. Revista de Educação e Informática, 9(13), 11-20.

Jacinski, E., \& Faraco, C. A. (2002). Tecnologias da educação: Uma solução ou um problema pedagógico? Revista Brasileira de Informática na Educação, 10(2), 49-56.

Magliano, J. P., Todaro, S., Millins, K., Wiemer-Hastings, K., Kim, H. J., \& McNamara, D. S. (2005). Changes in reading strategies as a function of reading training: A comparison of live and computerized training. Journal of Educational Computing Research, 32(2), 185-208.

Moraes, M. C. (1998). O paradigma educacional emergente. Campinas: Papirus.

Moran, J.M. (2004). Ensino e aprendizageminovadora com tecnologias audiovisuais e telemáticas. In J. M. Moran, M. T. Masetto \& M. A. Behrens. Novas tecnologias e mediação pedagógica (pp. 11-63). Campinas: Papirus.

Valente, J. A. (1999). O computador na sociedade do conhecimento. São Paulo: Ed. da Unicamp.

Recebido: 11/02/2010

Received: 02/11/2010

Aprovado: 19/05/2010

Approved: 05/19/2010 